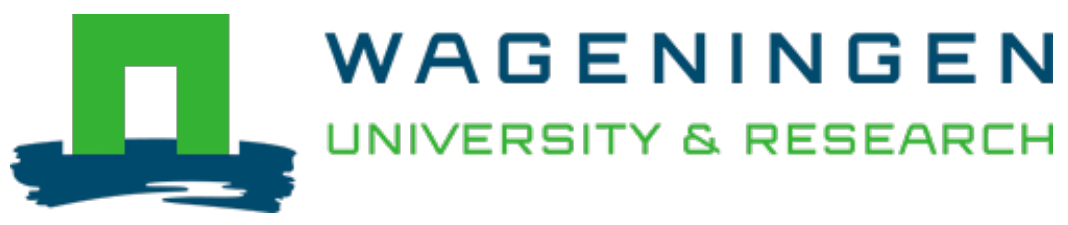

\title{
Using theatre and performance for greater reflexivity in planning and design education
}

\author{
Teaching Urban and Regional Planning \\ Buizer, I.M.; Lata, B. \\ https://doi.org/10.4337/9781788973632.00023
}

This publication is made publicly available in the institutional repository of Wageningen University and Research, under the terms of article $25 \mathrm{fa}$ of the Dutch Copyright Act, also known as the Amendment Taverne. This has been done with explicit consent by the author.

Article 25 fa states that the author of a short scientific work funded either wholly or partially by Dutch public funds is entitled to make that work publicly available for no consideration following a reasonable period of time after the work was first published, provided that clear reference is made to the source of the first publication of the work.

This publication is distributed under The Association of Universities in the Netherlands (VSNU) 'Article $25 \mathrm{fa}$ implementation' project. In this project research outputs of researchers employed by Dutch Universities that comply with the legal requirements of Article $25 \mathrm{fa}$ of the Dutch Copyright Act are distributed online and free of cost or other barriers in institutional repositories. Research outputs are distributed six months after their first online publication in the original published version and with proper attribution to the source of the original publication.

You are permitted to download and use the publication for personal purposes. All rights remain with the author(s) and / or copyright owner(s) of this work. Any use of the publication or parts of it other than authorised under article $25 \mathrm{fa}$ of the Dutch Copyright act is prohibited. Wageningen University \& Research and the author(s) of this publication shall not be held responsible or liable for any damages resulting from your (re)use of this publication.

For questions regarding the public availability of this publication please contact openscience.library@wur.nl 


\title{
11. Using theatre and performance for greater reflexivity in planning and design education
}

\author{
Marleen Buizer and Iulian Barba Lata
}

\section{INTRODUCTION}

Scholars of various disciplinary backgrounds increasingly regard the world as relational, as constituted through complex, networked and dynamic flows, and as hardly predictable (e.g., Buser 2012; De Roo and Boelens 2016). Relational thinking has entered spatial planning, urban and landscape design debates from geography since the turn of the century (Allmendinger et al. 2016; Murdoch 2006). The point of departure here is the role relational thinking had in unsettling some of the basic assumptions within spatial planning and design disciplines, thus bearing practical implications for the way research and education activities are organized. In this context, it is fairly commonplace to call for reflexivity and consider what are productive ways of incorporating relational thinking in education and training programmes for upcoming spatial planning and design practitioners?

Unlike positivist approaches that regard researchers as external-objective observers, relational and interpretive approaches regard researchers as immersed in the world they study, as participants and subjects (Healey 2007). While positivist approaches place the researcher in an objective, knowing position, relational and interpretive approaches involve as a key methodological tenet the critical engagement with the researcher's own values and normative frameworks. Here, 'theory' is not used to test and predict, but rather to explore and understand. In addition, while the former approaches pursue legitimacy and social change via outcomes produced from a detached stance, the latter involve the transformation of practice itself as a potential outcome. Therefore, advocates of interpretive research reject the positivist accounts that regard planners as being situated 'above politics' (Davoudi 2012; Healey 2013). Instead, they highlight the political nature of both formal institutional arrangements and informal processes. 
As compared with positivism, 'planning spaces' are considered more diverse and less predictable in such relational views. They raise complicated questions about the interplay of formal and informal approaches to area development, and between local and global forces (Allmendinger et al. 2016). Space, in this view, is not just a container of action and decision-making, rather it is socially produced and subject to embodied experience, "something that is (only provisionally) stabilized out of such turbulent processes" (Murdoch 2006, p. 4). Space thus appears as subjective, contested, political, and by no means an empty sheet, with planning and design processes being envisioned as iterative, interpretive, contingent and reflexive.

In a nutshell, the above sketches the conditions that sparked a growing concern with alternative educational approaches. We dwell upon these conditions at length, due to the various questions they raise for planning and design practices: In what ways do practitioners and researchers alike come to appreciate and work with such a diversity of knowledges and spatial imaginaries? What are productive means to stimulate thinking beyond their own disciplinary confines? How do they recognize the role of power in privileging some forms of knowledge over others? What are the possibilities of formulating questions and framing issues in collaboration with local participants, from the initiation of specific planning and design activities throughout their evaluation and transition into new types of activities?

These questions that involve a good deal of introspection are now indeed fairly common. However, there is a longstanding legacy of linear, functionalist thinking in spatial planning that often bypassed such questions. Given the normative assumptions about technical rationality, politics was hardly an issue for planning practices, even upon the emergence of collaborative approaches. The growing emphasis placed on relational thinking has, however, shifted attention to the context-specific character of technical rationality and the fact that planning processes are in every respect bound to power relations (Flyvbjerg 1998). Drawing on Henri Lefebvre's work (e.g., Lefebvre 1991), Davoudi contends that "[t]oo much emphasis on the 'conceived spaces' of planners and systems analysts would undermine the attempts to incorporate 'lived spaces' of imagination and 'perceived spaces' of daily routines" (2012, p. 434). On a similar note, Arjun Appadurai addresses the interplay between the 'ethics of probability' and the 'ethics of possibility', to argue that the dominant concern with the former as an expression of technical rationality should find a better balance with "those ways of thinking, feeling and acting that increase the horizon of hope, that expand the field of the imagination, that produce greater equity" (2013, p. 295). Granted this perspective, we are not advocating here for a complete turnaround towards relational thinking: different research questions require different approaches. Nevertheless, we do think that planning and design for uncertain outcomes and more diverse spaces (including the lived 
Table 11.1 Two theatre-based approaches in the classroom

\begin{tabular}{|c|c|c|c|}
\hline Theatre & $\begin{array}{l}\text { Theory-practice } \\
\text { reflections }\end{array}$ & Transformative routines & Reflexivity \\
\hline $\begin{array}{l}\text { Course I. BSc Planning } \\
\text { Theory ( } \pm 30 \text { students, } \\
6 \text { ECTS }=168 \text { hours, of } \\
\text { which } 42 \text { contact hours, } \\
\text { and } 126 \text { are self-study } \\
\text { hours) }\end{array}$ & $\begin{array}{l}\text { 'Playing/ } \\
\text { performing } \\
\text { theory' as lens }\end{array}$ & $\begin{array}{l}\text { Exploring iteratively the } \\
\text { interplay of theory and } \\
\text { practice in relation to } \\
\text { a common case study area }\end{array}$ & $\begin{array}{l}\text { In what ways do } \\
\text { different theoretical } \\
\text { lenses render different } \\
\text { insights? }\end{array}$ \\
\hline $\begin{array}{l}\text { Course II. MSc project/ } \\
\text { problem-based learning } \\
\text { ( } \pm 50 \text { students, } 9 \text { ECTS } \\
=252 \text { hours, of which } 96 \\
\text { contact hours, and } 156 \text { are } \\
\text { self-study hours) }\end{array}$ & $\begin{array}{l}\text { 'Playing/ } \\
\text { performing } \\
\text { theory' as lens }\end{array}$ & $\begin{array}{l}\text { Exploring iteratively the } \\
\text { diversity of 'planning } \\
\text { spaces' and envisioning } \\
\text { alternatives }\end{array}$ & $\begin{array}{l}\text { What are the factors } \\
\text { that enable/constrain } \\
\text { the emergence of } \\
\text { alternatives? }\end{array}$ \\
\hline
\end{tabular}

spaces of imagination and the perceived spaces of everyday routines) requires more attention in curricula. In this chapter we present a theoretically inspired teaching methodology that elicits such learning, in order to familiarize planning and design students with the multiplicity of spatial imaginaries.

Building on the previous work of one of the authors on transdisciplinary teamwork in research (Buizer et al. 2015), we will first focus on the use of Participatory Action Research (PAR) and transdisciplinary approaches in teaching. Secondly, we dwell on Goffman's (1959) theatre metaphor, which was developed into a heuristic for reflections on transdisciplinarity in research teams (Boyd et al. 2015). We have since further applied the approach in research and educational settings, and linked it to Judith Butler's (1986) concept of performativity. Lastly, our chapter will introduce two main instances of theatre-based approaches in the classroom (Table 11.1).

The first instance pertains to a course on planning theory and ethics. The course is critical of theory as providing evidence that frontloads research processes, leading to science-based interventions that are putatively the best for solving a predetermined problem. As an alternative, the course supports a relational take on theory, which requires a learning strategy for students to reflect on their own routines and roles, as well as encouraging them to question the rationale behind adopting certain theoretical approaches (Allmendinger 2009). The second instance concerns an MSc course, the 'Atelier Landscape Architecture and Planning', where theatre is used as a heuristic to reflect on the diversity of 'planning spaces' and related routine behaviours, as a means to envision alternatives. The theatre-based approaches are complemented by reflection sessions, which address the critical factors that either enable or constrain the emergence of transformative planning practices. 


\section{THEORETICAL INSPIRATIONS}

With the current emphasis at our university (and elsewhere, both in academic policy and rhetoric) to deliver 'Science for (societal) Impact', transdisciplinary and participatory methodologies seem to receive more attention. However, Participatory Action Research and transdisciplinarity are also contested, with some arguing that they are mainly benefiting elites and often failing in their pursuit of structural social change (Whitzman 2017). At the same time, they have been recognized for spurring critical reflection on researchers' own responsibility for the places and communities in which they operate (Susskind et al. 2018). They are often invoked in the context of addressing 'wicked problems' such as climate change, food insecurity, poverty and social exclusion (Boyd et al. 2015). PAR approaches represent a necessary addition to the more prominent positivist toolkit of planning and design students, thus enabling educational strategies that promote an "attitude of adventure" (Davoudi 2012, p. 432) and exploration, as a viable alternative (Pinel and Urie 2017).

Participatory methodologies are still at the periphery of teaching programmes, and habitually at odds with the routines associated with them. A key issue therefore is to obtain an in-depth understanding of those routines, the conditions and potential impediments for transitioning towards transformative practices. Here, we draw on the work of Goffman (1959), who emphasizes that social actors in everyday interactions 'perform' in a way they think it is expected from them, a process he coins impression management. By managing impressions, actors avoid embarrassment, on their own behalf and on behalf of others. Routines and rituals, established and continuously re-enacted, become normalized through particular behaviours, professions or everyday practices. This does not imply that actors are just managing impressions as merely 'cynical', 'calculative' strategists, but rather that they "protect social continuity" (Giddens 1984, p. 70).

With the predominant focus on behaviour and everyday interactions, Goffman's work has only occasionally been associated with the discussion of power relations (Jenkins 2008). His interactional sociology has received some criticism for overemphasizing the role of everyday face-to-face interactions at the expense of structural forces. However, as Jenkins asserts, this is a misplaced critique that does not sufficiently acknowledge how Goffman's ideas are corresponding with Foucault's attention to power and discourse as part of day-to-day routines. Drawing on Tom Burns's work, Jenkins concludes that "in fact the two theorists (Goffman and Foucault) share a considerable amount of common ground with respect to the normalization of order and the routine everyday ubiquity of power, its mundane invisibility" (Jenkins 2008, p. 158; see also Hacking 2004). 
For our translation of Goffman's ideas into a heuristic that elicits reflections on planning and design routines, we argue for a more explicit recognition of the power dimension. Power is thus interpreted as relationally enacted in everyday normalised routines, through specific action repertoires such as sketching, mapping and storytelling. As Alan Read suggests, the "story does not express, describe or illustrate a practice, it makes movement and practice possible in the first place. To move into a place there is the need for a story about it" (1995, p. 153).

In order to consider what are normalized routines and how those might foreclose alternative forms of expression and reflection, theatre-based approaches have proven instrumental for our teaching. We can use the theatre metaphor to ask what is the stage like, whether it is on the same level with the audience, like in street theatre, or at a distance? What props are 'normally' used, and what kind of performer-audience relationships can be imagined? Is there room for improvisation and to what extent is such considered desirable? We also habitually question the role of the script writer and director, as well as that of the cast. And is there a backstage of any significance, to reflect on the performance? Alternatively, we can actually 'play' with the metaphor as we did in the two courses that we will present in the next section.

At the same time as gaining an understanding of routine behaviours, one can ask how scrutinizing routines may enable imagining alternatives, and empowering participants (students or researchers). Indeed, there is much to science practices that is routine, or to use the metaphor of theatre, staged and scripted: the role of the 'knower' as a neutral player that provides 'the science' to support specific interventions, the setting of the university campuses and their buildings, the scripts whereby teachers are expected to transfer knowledge to their 'audience of students' or where scientists are to provide legitimacy to policy decisions. To draw a parallel with Peter Brook's work on theatrical performance, "[t]ruth in theatre is always on the move" (1996, p. 140). In sum, we can easily think of academic teaching and research practices in terms of Goffman's theatre metaphor and come to understand it as 'performed identity'.

The power dimension of performance is more explicitly present in the work of Judith Butler. According to Butler, identities are constructed, performed. She presents the notion of performativity to clarify how the repeated 'doing of gender', makes gender, or in paraphrasing Simone de Beauvoir: "one is not born, but rather becomes, a woman" (1986, p. 35). Correspondingly, science is 'performed' by engaging in scientific practices such as conducting research, peer-reviewing, attending conferences and lecturing. Whereas performance may be the one-off manifestation of scientific identity via the aforementioned practices, their repetitive character normalizes them into routines and renders them performative. The optimistic turn we take with regard to Goffman concerns the use of theatre to reflect on students' own positionality, exposing 
routine behaviours and evaluating their implications for the emergence of alternatives. This is usually an effective strategy, which enables students to develop new types of routines and to better grasp the interplay between theory and practice.

\section{Course I: (BSc) Learning about Theory through Theatre}

When obtaining their University Teaching Qualification (UTQ or BKO), educators at our university are trained to distinguish learning objectives in three distinct domains: the cognitive, affective and sensory domains, focusing respectively on cognitive knowledge, attitudes and practical skills (Anderson et al. 2001). Unsurprisingly, the cognitive domain is prevalent in university curricula. In tune with the overemphasis on expert knowledge, as critically discussed above, the researcher or professional are often depicted as gatekeepers to knowledge, those able to understand, provide the evidence and develop interventions accordingly. The future job of our students! However, this conception of knowledge that renders interventions 'evidence-based' may be at odds with the complex situations our graduates often encounter in practice. Our weekly theatre aims to nurture an open attitude towards the complexity and context-specific character of those situations, the ambivalences and dilemmas of planning and design tasks, as well as the multiple ways in which theory could become meaningful when 'applied' to practice. In the course called 'Planning Theory and Ethics', later renamed 'Concepts and Approaches for Planning Practices', spatial planning theories and concepts are considered as 'sensitizing' (Blumer 1954) and (adjustable) 'lenses', rather than evidence (see Figure 11.1).

The planning-theoretical 'lenses' discussed in the study year 2017-18 were:

1. Rationalism versus Phronetic Planning Research

2. Discourse and Narrative

3. Formality/Informality and the 'unplanned'

4. New Planners: urban curators and temporality

The course runs for 8 weeks (mornings) and started in this with a study trip to a post-industrial site in The Hague (Binckhorst), which is being transformed into an area for living and working. We chose only one case to provide for a shared focus. The study trip consisted of an introduction by several stakeholders to the specific challenges in Binckhorst and a full-day exploration of the area. Thereafter, in a weekly series of activities, the second year bachelor students (specialization in planning, part of a joint programme with landscape architects) read the selected texts and write reviews (after a short e-module 'writing good reviews'), participate in an extended lecture on the 'theoretical 
lens' of the week, define the key ingredients of the studied theoretical approach and, based on those, they either develop a script for or assess the 'Theory Theatre' performances. The final assignment is an essay in which students need to reflect on the case area by selecting of the theoretical lenses.

By following this sequence, different ways of thinking and learning are mobilized: the more traditional 'reading and summarizing'; working on small classroom activities that explore theory and concepts in light of the case study area; talking and deliberating with other students when preparing the script and rehearsing (a first step that involves theory-practice embodied performance); the performance itself. In this course, we do not provide the Goffman inspired elements of theatre (as we do in the MSc course) but invite students to literally perform theory in relation to an imaginary situation, which unfolds in the case area. By doing so, we 'flip the classroom': students take the lead in developing and sharing the content.

In the Theory Theatre, students work in groups of 3-5. Each week, half of the groups perform, while the other half act as a 'jury'. While the performing teams prepare and rehearse their contribution, the jury elaborates the substantive elements from theory that are expected to be included in the performance. The jury also evaluates the performers' skills in conveying their message convincingly, since theory and related concepts often afford a broad range of (creative) translations into the theatre performances. A recurrent point of discussion was whether the performers interpret theory in a normative manner (such that they would use it to prescribe alternative ways of planning/designing) or as analytical lens (facilitating a more in-depth understanding of a phenomenon). Another important aspect pertained to intentionality and the choice of performance. For instance, some groups opted to convey their message through video materials, while others used poetry, dance and/or music acts. With such a diverse range of performances, we saw that jury-groups started to include elements like 'creativity' and 'participation from the audience' in their evaluation. A short feedback session concluded each performance, in which the jury passed the evaluation and discussed it with the performing team and the audience.

Upon completion of the course, students were able to:

1. Compare different planning theories and practices in a historical and international perspective

2. Distinguish and evaluate the ethical dimensions of the spatial planning profession

3. Evaluate existing planning situations in the light of theories and ethics of spatial planning

4. Creatively connect theoretical perspectives to practical situations

5. Write reviews and an essay in well-written language 


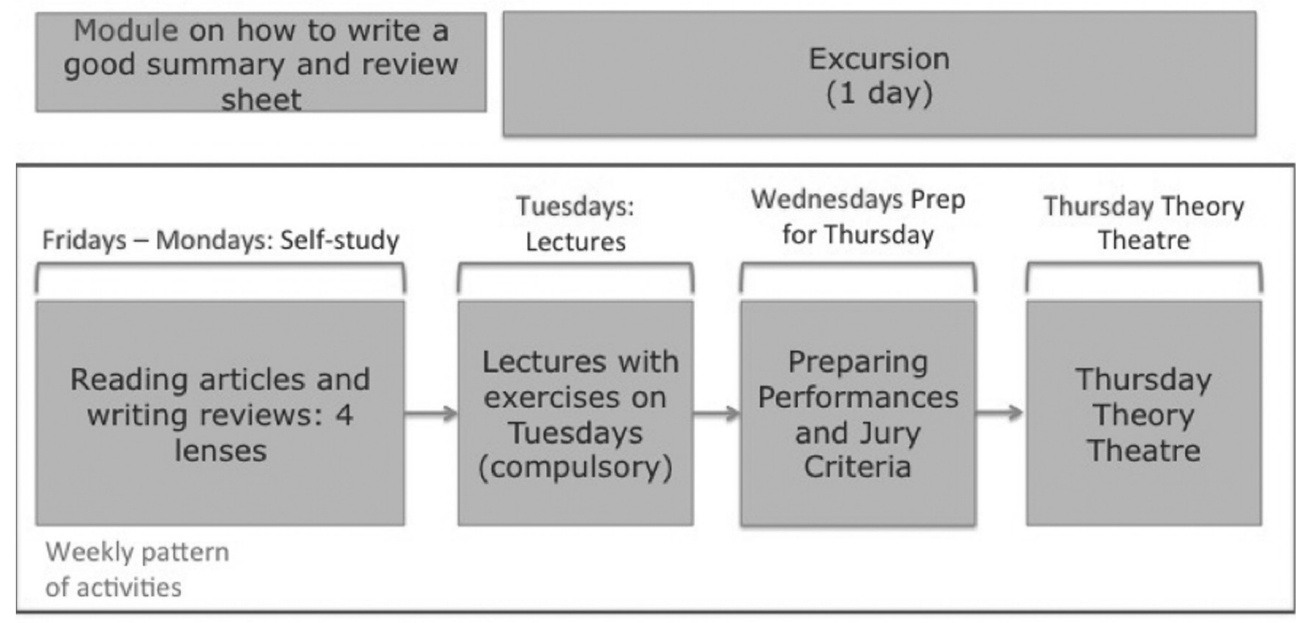

Essay (individual)

Figure 11.1 The course and its elements

As teachers, our main lessons may be summarized as follows:

1. Adding theatre to the mix of teaching activities as a way to 'flip' the classroom, enables students to actually work with theory and develop new insights when reflecting on practice situations.

2. Students often remain close to their own setting and experiences when translating the theoretical lens to a practice situation. For instance, situations that the students knew well (such as living in student dorms) were more frequently used to explain theory and related concepts than the less-familiar particularities of the case area.

3. In preparing their theatre performances, student teams opted for all sorts of alternative formats: a 'Twister' inspired game that connects theory to practice, a quartet, a route that peers need to explore blindfolded, while following instructions inspired by the theoretical approach. Other formats included quizzes, short films, songs (translating a theory into lyrics and music), poetry, rap with dance, storytelling, a house of commons debate and even a flash-mob (on one occasion the class decided to perform as a combined group, to the surprise of the teachers).

4. The practice of translating and contrasting theory to practice incorporated interpretations that sometimes remained implicit or obscure to the audience. Having a narrator as part of the performance, could facilitate more focused discussions on how the team evaluated theory. 
The course was given for the first time in 2015 and won a student award in 2016, just as the course that we will discuss next.

\section{Course II: (MSc) Reflexivity through Theatre in Project}

Landscape architecture and planning are intervention and future-oriented disciplines, which rely to an important extent on the development of creative skills. In our BSc and MSc programs Landscape Architecture and Planning, studio education is important - students create, often by hand, future scenarios or designs. Calls for the programme to frontload those scenarios/designs with 'scientific evidence', demanding a high level of cognitive knowledge, are still strong. We felt a heuristic was needed to critically reflect on this type of learning routines.

The second course in which we work with theatre is the MSc Atelier Landscape Architecture and Planning. Rather than focusing on content (theoretical and practical), significant attention goes to explicit reflections on students' personal development and their teamwork in a context of conducting transdisciplinary research and design work. Not knowing beforehand what will evolve from their process of engagement with local actors, there is an important element of crafting solutions 'on the go', whilst constantly exploring and problematizing dominant problem definitions. There is often an uncomfortable tension between the design practice of 'crafting on the go' and the claims to 'scientific evidence' mentioned above.

The atelier is an intensive, integrative course, which aims to bring together the insights and experience MSc students have gained during the first year of their Master's. It is the last course before they start working on their thesis and internship. With a CV and a motivation letter, students apply to work on a project of their choice. In the months preceding the course, their teachers (called 'coaches') formulate rough outlines in consultation with the commissioners. Students discuss the assignments in more detail with their commissioner during the first two weeks of the course.

Each year, the atelier offers different projects and hosts a variety of project teams under an overarching theme. Research, planning and design activities in the spirit of the designated theme require different approaches, which depend on aspects such as the scale of the project, the people involved, the level and nature of potential contestation or support, and the type of solutions sought.

All projects in the atelier have a research component on the one hand, and a design and planning component on the other. In consultation with their commissioners, who can be as diverse as government officials, NGO representatives, artists or volunteers, students decide on the types of activities required, the outcomes to be achieved and the products to be delivered. Depending on the type of task at hand and the project phase, research activities are balanced 
with design and planning activities. Usually, the preliminary project phases are defined by more research focused activities, while the later ones tend to rely mainly on intervention-focused activities.

The course is organized before the summer, throughout 8 weeks, in order to allow for good field immersion. The students work in groups of 5-7, in one studio space, to allow for cross-group exchanges. The majority consists of landscape architects, one in five is a spatial planner, and there is also a small number of students from other disciplines, such as ecology or urban engineering. Room dividers offer space for displaying their intermediate products.

The learning objectives of this course are summarized as follows:

1. Interpret and investigate the multiple aspects of a landscape challenge

2. Develop a planning and design proposal in response to a landscape challenge, which is supported by research findings and related ethical issues

3. Present the strategy or design in a form that meets the agreements made with the client, whilst offering transparency about the entire process

4. Reflect on the experience of acting in a multi-disciplinary team and the relation of the team to the client, both in an assessment interview and by writing an individual assessment paper

5. Assess the contribution of team members and other stakeholders to the team performance and the execution of project tasks

As part of the course, the students formulate personal development objectives at three levels: individual, team, transdisciplinary. The theatre exercise is organized half-way through the course. After the first four weeks, the students have acquired sufficient experience with teamwork, and most have faced the first hurdles. We then introduce Goffman's work and the theatre metaphor. The students are invited to write a script in two parts, with one part that presents a routine practice, and a second part that envisions a future routine. The groups film their performances, and after each team's performance, the other groups provide feedback. What did they 'see' in the performance? Did they have similar experiences in their own group or when working with commissioners and other social actors? How did they respond? What are their views on the proposed alternative? How does the performing group evaluate the received feedback? We ask the students to summarize their findings in writing.

As coaches, our main findings from the activities are the following:

1. Students generally stay 'close to home' in their performances in the atelier. For example, a recurring topic is 'arriving on time in the mornings', 'taking time for informal coffee breaks' and the timing of meetings. Routines relating to the planning and design profession are more difficult to pinpoint for the students. We expected that doing the exercise mid-way the course (instead of the beginning), would help groups choose routines 
a little more related to their transdisciplinary fieldwork for example. In their evaluations of the course, the students indicate that their work in the atelier is quite different from the experience of other courses, mainly in terms of the intensity of the engagement with actors in the field, that they are designing for. The fact that they choose to focus on routines in their teams rather than in their engagement with stakeholders in their project areas is probably a result of the lack of experience with such engagement. Perhaps doing a second exercise at the end of the course, giving examples, or asking experienced people to introduce the topic of co-designing, might provide insights that would enable the students to focus more on the transdisciplinary orientation. Yet, the question remains of how effective such an approach would be at this stage of the professional development of students. (A similar observation was made when the exercise was conducted with postdoctoral researchers - their interdisciplinary group work was still such a challenge that they could not think in terms of routines yet, when it came to engagement with non-academic actors.)

2. A second frequent topic is penalties. Groups set informal rules and when these are broken, they may work with penalties like having to bring cake for the others when running late for appointments. In the 'routine' version of the play, they do not have such a system, in the alternative they do.

3. Groups that had more intensive interactions with their commissioners tended to reflect more on those in their performances. For example, one group struggled with a versatile, demanding commissioner, whose views were often not recognised as representing the opinions of people from the community. Here the question of conflicting identities arose - should the group act as consultants and deliver a product in conformance with the demands of their commissioner, or should they prioritize the results of their interviews? To what extent could these two roles be aligned? The performance gave rise to a vivid discussion with other student teams and eventually the group decided to take the lead in responding to the commissioner.

4. In some groups, students have opted to perform the role of their colleagues. This demands a friendly atmosphere and high level of trust within the team, whereby the group could agree, for instance, on exaggerating each other's personas. In this case, theory theatre helped the group to become more open about their group dynamics. Other groups realised the importance of humour as a factor that could help open up a conversation about an otherwise awkward topic. 


\section{DISCUSSION AND CONCLUSION}

To prepare our graduates to enter an increasingly complex and dynamic world in which uncertainty, struggle and conflict are more common than predictability, consensus and straightforward collaboration, we employed theatre-based approaches in two ways:

- as an exploratory device to evaluate the interplay of theory and practice

- as a heuristic to uncover the diversity of 'planning spaces' and related routines in opening a conversation about alternative behaviours.

In both instances, embodied performance added to the learning experience a layer based on practical skills and a reflexive attitude. In the first instance, 'theory theatre' enabled a playful development of cognitive knowledge and linked the early-curriculum acquaintance with theories, to questions about their meaning for practice situations in which the position of the theorizing explorer also matters. In the second instance, we drew on methodologies such as PAR, and emphasized the role of transdisciplinarity and its challenges. Theatre was used to reflect on the multiple imaginaries and routines that inform planning processes and their broader implications for developing alternatives, i.e., more inclusive and transformative planning practices. We envisioned this would assist in enhancing reflexivity by: (a) involving different researchers, professionals, practitioners and communities throughout the design and planning processes; (b) problematizing (dominant) problem framings; (c) viewing 'knowledge' in terms of 'knowledges' or 'knowledge claims'; and (d) focusing on 'knowledge production' as a verb (Rydin 2005). During the early stages of their performances, students were more concentrated on their teamwork than on their relationship with other societal actors. However, when they did adopt the latter focus, the performances rendered lively discussions that other students could easily relate to.

To facilitate a view/practice of 'science' that embraces a reflexive, 'on the go' learning modality at its core, we presented a teaching strategy inspired by Goffman's imagery of theatre. In attempting to go beyond mere (cognitive) understanding, with students' theatre performances alternatives become actualized through embodied practice. To an extent, change is already enacted. (See Box 11.1.)

\section{BOX 11.1 MAIN CHALLENGES AND SUGGESTIONS}

- We found the traditional classroom layout a practical challenge, as before each theory theatre session we had to reshuffle the furniture. In 
some cases, the classroom furniture was creatively used for the stage setting performances.

- While the theatre-based approaches are quite prominent in the set-up of the two courses, we consider the role of additional assignments (reviewing, jurying, contributions to a course repository, writing a final essay) equally important in meeting the learning objectives (both individual and group ones) assigned to the program and evaluating the proposed learning strategy.

- With the theatre performances it is important to provide enough time for discussing interpretations, whilst challenging the students to debate both form and contents. Using short breaks to transition from performances to reflections with the audience usually allows students to better formulate their questions and comments.

- As the interplay between theory and practice represents a key ingredient of the theatre-based learning strategy, we always relate to a concrete case and its particularities - a common case study area for the BSc course, and the commissioned projects in the MSc atelier.

- Given the interactive format and the load of additional assignments, teamwork is key to a successful preparation of the course. A team of two lecturers and one student assistant would be optimal.

\section{REFERENCES}

Allmendinger, P. (2009) Planning Theory. Basingstoke: Palgrave Macmillan.

Allmendinger, P., Haughton, G., and Shepherd, E. (2016) Where is planning to be found? Material practices and the multiple spaces of planning. Environment and Planning C: Government and Policy 34(1): 38-51.

Anderson, L. W., Krathwohl, D. R., Airasian, P. W., Cruikshank, K. A., Mayer, R. E., Pintrich, P. R., Raths, J. and Wittrock, M. C. (2001) A Taxonomy for Learning, Teaching, and Assessing: A Revision of Bloom's Taxonomy of Educational Objectives. New York: Pearson, Allyn \& Bacon.

Appadurai A (2013) The Future as Cultural Fact: Essays on the Global Condition. London: Verso Books.

Blumer, H. (1954) What is wrong with social theory? American Sociological Review 19(1): 3-10.

Boyd, D., Buizer, M., Schibeci, R. and Baudains, C. (2015) Prompting transdisciplinary research: Promising futures for using the performance metaphor in research. Futures 65: 175-184.

Brook, P. (1996) The Empty Space - A Book about the Theatre: Deadly, Holy, Rough, Immediate. New York: Simon \& Schuster.

Buizer, M., Ruthrof, K., Moore, S. A., Veneklaas, E. J., Hardy, G. and Baudains, C. (2015) A critical evaluation of interventions to progress transdisciplinary research. Society and Natural Resources 28(6): 670-681.

Buser, M. (2012) The production of space in metropolitan regions: A Lefebvrian analysis of governance and spatial change. Planning Theory 11(3): 279-298. 
Butler, J. (1986) Sex and gender in Simone de Beauvoir's Second Sex. Yale French Studies 72: 35-49.

Davoudi, S. (2012) The legacy of positivism and the emergence of interpretive tradition in spatial planning. Regional Studies 46(4): 429-441.

de Roo, G. and Boelens, L. (2016) Setting the scene: About planning and a world in change. In G. de Roo and L. Boelens (eds.), Spatial Planning in a Complex Unpredictable World of Change: Towards a Proactive Co-Evolutionary Type of Planning within the Eurodelta (pp. 14-27). Groningen: InPlanning.

Flyvbjerg, B. (1998) Rationality and Power: Democracy in Practice. Chicago, IL: University of Chicago Press.

Giddens, A. (1984) The Constitution of Society: Introduction to the Theory of Structuration. Berkeley, CA: University of California Press.

Goffman, E. (1959) The Presentation of Self in Everyday Life. New York: Anchor Books.

Hacking, I. (2004) Between Michel Foucault and Erving Goffman: Between discourse in the abstract and face-to-face interaction. Economy and Society 33(3): 277-302.

Healey, P. (2007) Urban Complexity and Spatial Strategies: Towards a Relational Planning for Our Times. London: Routledge.

Healey, P. (2013) Circuits of knowledge and techniques: The transnational flow of planning ideas and practices. International Journal of Urban and Regional Research 37(5): 1510-1526.

Jenkins, R. (2008) Erving Goffman: A major theorist of power? Journal of Power 1(2): $157-168$.

Lefebvre, H. (1991) The Production of Space. Oxford: Blackwell.

Murdoch, J. (2006) Post-Structuralist Geography: A Guide to Relational Space. London: Sage Publications.

Pinel, S. L. and Urie, R. (2017) Learning reflective planning: The application of participatory action research principles to planning studio design and assessment. Journal of Architectural and Planning Research 34(1): 32-48.

Read, A. (1995) Theatre and Everyday Life: An Ethics of Performance. London: Routledge.

Rydin, Y. (2005) Geographical knowledge and policy: The positive contribution of discourse studies. Area 37(1): 73-78.

Susskind, L., Cunningham, D. and Cruxén, I. A. (2018) Teaching participatory action research: The search for pedagogical insights. In L. Susskind, D. Cunningham and I. A. Cruxén (eds.), (Participatory) Action Research: Principles, Approaches and Applications (pp. 125-150). New York: Nova Science Publishers.

Whitzman, C. (2017) Participatory action research in affordable housing partnerships: Collaborative rationality, or sleeping with the growth machine? Planning Practice and Research 32(5): 495-507. 